\title{
Anthropogenic Nest Materials May Increase Breeding Costs for Urban Birds
}

\author{
Monserrat Suárez-Rodríguez ${ }^{1}$, Regina D. Montero-Montoya ${ }^{2}$ and \\ Constantino Macías Garcia ${ }^{1 *}$ \\ 'Departamento de Ecología Evolutiva, Instituto de Ecología, Universidad Nacional Autónoma de México, México, Mexico, \\ ${ }^{2}$ Departamento de Medicina Genómica y Toxicología Ambiental, Instituto de Investigaciones Biomédicas, Universidad \\ Nacional Autónoma de México, México, Mexico
}

Even in socially monogamous species, sexual conflict is one reason that often promotes differences in the roles of sexes during reproduction, which may lead to one sex making a disproportionate contribution, and thus incurring disproportionate costs, at particular moments of the breeding process. In Mexico City, a number of songbird species line their nests with fibers from discarded cigarette butts, which reduce ectoparasite load but are genotoxic. As male Passer domesticus make substantial contributions to nest building whereas male Carpodacus mexicanus do not contribute to nest building, we hypothesized that the toxic effects of exposure to cigarette butts should be greater for females $C$. mexicanus than for conspecific males, but that there should be little or no

OPEN ACCESS

Edited by:

Caroline Isaksson, Lund University, Sweden

Reviewed by: Adele Mennerat, University of Bergen, Norway Åsa M. M. Berglund, Umeå University, Sweden

*Correspondence: Constantino Macías Garcia maciasg@unam.mx

Specialty section: This article was submitted to Urban Ecology,

a section of the journal Frontiers in Ecology and Evolution

Received: 28 September 2016 Accepted: 19 January 2017

Published: 03 February 2017

Citation:

Suárez-Rodríguez $M$, Montero-Montoya RD and Macías Garcia C (2017) Anthropogenic Nest Materials May Increase Breeding Costs for Urban Birds.

Front. Ecol. Evol. 5:4. doi: 10.3389/fevo.2017.00004 difference in $P$. domesticus. As expected there was more exogenous genotoxic damage in the red-blood cells of incubating female C. mexicanus the more cigarette butts were found in their nest, and much more than in their conspecific males. Damage in males was not associated to cigarette butts; it was initially lower than in females, but it increased near fledging, together with their breeding effort. In both male and female P. domesticus, however, genotoxic damage was equally apparent and greater the more cigarette butts were in the nest. The novel use of a toxic, anthropogenic parasite repellent by urban birds may be thus asymmetrically increasing the breeding costs paid by the member of the pair most involved in nest building and incubation.

Keywords: cigarette butts, genotoxicity, Carpodacus mexicanus, Passer domesticus, parental care, sex roles

\section{INTRODUCTION}

Human activities impact the environment in a variety of ways, often with negative consequences for the local biota (Miller and Hobbs, 2002). This is clearly the case with urbanization, where organisms are exposed to a new array of stressors that impose substantial constraints on their biology (Ditchkoff et al., 2006). Behavioral modifications are amongst the first responses of animals to life in the cities (Baldwin, 1896; Price et al., 2003). This is because behavior can be speedily adjusted through learning, thus providing a rapid means to adapt to new conditions (Ditchkoff et al., 2006; Sih et al., 2011; Sih, 2013). For instance, the plasticity of Passeriformes' song production (Slabbekoorn, 2013) allows them to make instantaneous adjustments of frequency in response to sudden increases of anthropogenic noise, as has been experimentally shown by BermúdezCuamatzin et al. (2010) and Gross et al. (2010). Other examples include short-term increases in competitive behavior of invasive crabs (Tanner et al., 2011) and changes of time budgets in birds near airports (Gil et al., 2014). 
Animals may modify behaviorally to an array of human disturbances. Thus the negative effects of habitat fragmentation may be contended with by adjusting dispersal and foraging patterns (Rathcke and Jules, 1993; Hovland et al., 1999; Tscharntke and Brandl, 2004; Schtickzelle et al., 2006). For instance, the bog fritillary butterfly (Proclossiana eunomia) show a dispersal depression in fragmented landscapes, as dispersal between landscape fragments is linked to high mortality (Schtickzelle et al., 2006), whereas root voles (Microtus oeconomus) forage preferentially on the edges of fragmented landscape patches (Hovland et al., 1999). Human alteration of the environment often involves the translocation of organisms. For instance, urban biota is increasingly comprised of non-native species, which may negatively interact with native organisms. Consequently, prey species often have to adapt their behavior to the presence of invading predators, whereas competing local species may need to escalate competition to reduce the negative effects of such introductions (Sih et al., 2010). Equally insidious is the effect of invasive species on the local species mating systems (e.g., Valero et al., 2008).

Humans also modify the environment by polluting it. In particular, anthropogenic chemicals may interfere with the expression of sexual traits such as coloration, courtship or singing performance (Gorissen et al., 2005; Markman et al., 2008) partly because they often act as hormonal disruptors, which may provoke changes in the operational sex-ratio, thus interfering with mating behavior (Fry, 1995). A complex form of pollution is that caused by solid waste. This is composed of discarded traces of products used by humans. A sometimes large fraction of the consumables that we use is discarded; it is mostly unfriendly with the environment and may take a long time to degrade. Several types of solid waste are harmful to humans, animals and the ecosystems (Hamer, 2003). Humangenerated waste is ubiquitous in cities and elsewhere, and, as it often resembles natural materials, it is frequently used by mammals (Cavia et al., 2009) and birds (Wang et al., 2009; Votier et al., 2011; Townsend and Barker, 2014) in the construction of their nests. Since the distribution and physical properties of waste products is not the same as those of natural materials, the use of waste products requires behavioral adjustments, such as the ripping-of and unweaving of cigarette butts to line nests (Suárez-Rodríguez et al., 2013). Given the paramount influence of the nest materials on the microclimate and the biota to which developing offspring are exposed (Collias, 1964; Hilton et al., 2004), incorporating anthropogenic materials on the nests is likely to have a major influence on the natural history of those using them (Hartwig et al., 2007; Wang et al., 2009; Antczak et al., 2010; Suárez-Rodríguez et al., 2013).

Eggs and chicks are directly in contact with the nest lining; a thin soft structure of feathers, fur and the like. Often, it also includes green plant materials that serve to repel ectoparasites (e.g., in the common starling Sturnus vulgaris; Clark and Mason, $1987,1988)$ as they contain secondary metabolites evolved to prevent herbivory (Wink, 1988; Wittstock and Gershenzon, 2002). In other species such as blue tits (Cyanistes caerules), green materials seem to act against bacteria in the skin of chicks (Mennerat et al., 2009a) which is linked with faster mass gain
(Mennerat et al., 2009b). Note, however, that the same materials may be added for reasons unrelated to egg/chick wellbeing. For instance, in spotless starlings (S. unicolor) the addition of green plant material to the nest serves mainly as a sexually selected signal that stimulates the production of testosterone in females, and may also signal male status (Veiga et al., 2006; Polo et al., 2010). Some bird species use this strategy to repel arthropods from their nests (Wimberger, 1984; Gwinner and Berger, 2006; Ontiveros et al., 2007) thus it has been considered a way of actively protecting the nest from ectoparasites (Clark and Mason, 1988). Bird ectoparasites are a well-known to be harmful, especially those occupying their nests (Clayton et al., 2010; Hund et al., 2015; also see López-Rull and Macías Garcia, 2015).

In addition to natural materials, two common city birds, P. domesticus and C. mexicanus weave anthropogenic materials (Van Riper III, 1976), including cotton fibers from discarded cigarette filters into the nest lining (Suárez-Rodríguez et al., 2013). Cigarette butts have a repellent effect similar to that of green materials (Suárez-Rodríguez et al., 2013), yet they also contain many toxic substances in addition to Nicotine, such as ethylphenol, heavy metals (e.g., titanium dioxide), propylene glycol, diverse insecticides, and even cyanide (Witschi et al., 2002; Jensenl et al., 2004; Moriwaki et al., 2009; Slaughter et al., 2011; Register, 2013). Thus chick erythrocytes show signs of genotoxic damage proportional to the amount of cigarette butts used to line their nests (Suárez-Rodríguez and Macías Garcia, 2014), probably as the toxic substances enter their bodies through their skins, which are in contact with the nest materials. Although we cannot exclude the possibility that at least those that are volatile are also inhaled. Genotoxic damage occurs when an exogenous or endogenous agent (including reactive oxygen species) breaks DNA chains during mitosis, a process that can lead to mutagenicity and eventually to carcinogenic processes (DeMarini, 2004; Valko et al., 2004; Fenech, 2007). DNA damage results in nuclear abnormalities, with cells containing a nucleus plus one or more micronuclei, or bi-nucleated cells with bridged nuclei. Damage to the mitotic apparatus (microtubules and microfilaments) results in true bi-nucleated cells (with a duplicated genome; Fenech, 2007). While some damage may go undetected upon visual inspection, standardized counts of cells with nuclear abnormalities can be used as direct measures of genotoxic damage (Fenech, 1997).

Contact with discarded cigarette butts is toxic to chicks (Suárez-Rodríguez and Macías Garcia, 2014), and perhaps also to adults. Thus, by lining their nests with such materials, urban P. domesticus and C. mexicanus may be exposing themselves to a novel breeding cost, which we expect to differentially affect males and females given their unequal share of the breeding activities. Here we conducted standardized counts of damaged erythrocytes to quantify the cost incurred by male and female $P$. domesticus and C. mexicanus at different moments in their breeding season (stages). We hypothesized that the amount of direct contact with cigarette butts through manipulation and incubation should be positively correlated with genotoxic damage, and should thus differ between sexes and species in accordance to their breeding roles. We tested the above on the house finch and the house sparrow. These species coexist in North American 
cities, where they occupy similar ecological niches (Bent and Austin, 1968; Woods, 1968; Lowther and Cink, 2006), to the point that competition often occurs between them (Kalinoski, 1975; Bennett, 1990; McClure et al., 2011).

\section{METHODS}

\section{Study Species}

Carpodacus mexicanus (Müller, 1776), a native finch from North America (see Figure 1), is a socially monogamous bird with well-defined sexual roles and sexual dimorphism in color -adult males displaying bright carotenoid-dependent red crowns, bibs and rumps- as well as a large song repertory. Females are less conspicuous and choose males for their color and their songs (Nolan and Hill, 2004). Females are more actively involved in parental care than males, at least initially. They choose the nest site, build the nest, incubate the eggs and participate in the feeding of the chicks, whereas males feed the female during the incubation and do most of the feeding of fledglings, often also taking over the feeding of pre-fledging chicks (Hill, 2002).

Passer domesticus (Linnaeus, 1758), the ubiquitous house finch (see Figure 1), is a socially monogamous European finch long naturalized in the Americas. It is also sexually dimorphic. Male ornaments (maroon and gray crown, black patches around beak and the eyes, a black bib, and dark back and wings that contrast with their pale underparts) are due to melanin, while females lack contrasting patches and seem drabber. Parental care is shared between sexes; both members of the pair choose the nest site, build the nest, incubate the eggs (female more actively) and feed the chicks (male more actively; Voltura et al., 2002; Hoi et al., 2003; Schwagmeyer et al., 2005; Liker et al., 2008).

\section{Study Site and Blood Samples}

We conducted this study in a mixed colony of $C$. mexicanus and $P$. domesticus at the main campus of the Universidad Nacional Autónoma de México (UNAM) in the south of Mexico City.

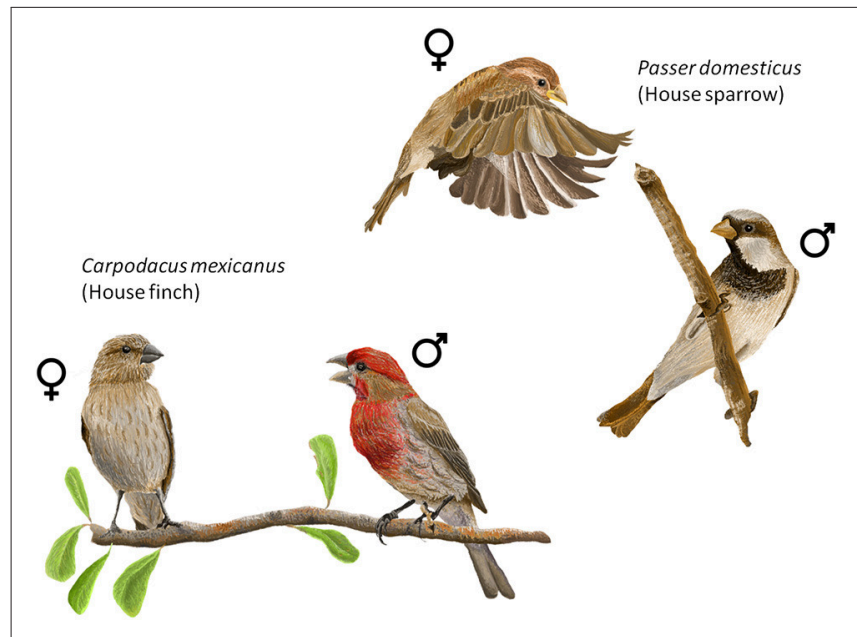

FIGURE 1 | Female (far left) and male Carpodacus mexicanus (left), female (right) and male (far right) Passer domesticus (drawings by MSR).
These species were breeding in natural conditions, constructing their nests on building structures or in trees. We worked with a mixed-species colony where nests are placed in close proximity (from $30 \mathrm{~cm}$ to $200 \mathrm{~cm}$ ). Here, pairs of both species interact with each other throughout the breading season, feeding and collecting nest materials from the same places. Discarded cigarette butts are available on the ground, and are locally abundant at particular spots around the gates of the surrounding buildings. In the spring of 2014 we monitored the activity of the colony with binoculars (Minox ${ }^{\mathrm{TM}} \mathrm{BV} 10 \times 42$ ) to assess the breeding stage and the number of eggs or chicks. We captured both members of each pair by setting mist nets for 3 days at the end of each of four 15-days intervals starting 15 days after the majority of the pairs had begun nest building. We could not recapture both members of the pair at all breeding stages, and this was declared in our statistical models. Thus we sampled breeding adults at end of (a) nest building, (b) incubation, (c) early (chicks $\leq 15$ days old) and (d) late breeding (chicks $\geq 16$ days old). Rodnan et al. (1956) reported that after 30-40 days radioactively marked erythrocytes were no longer present in pigeon (Columba livia) chick (Gallus domesticus) and duck (Anas platyrhynchos) blood samples, and from the reported curves it can be inferred that between 40 and 50\% erythrocytes are removed from the bird's circulating blood every 2 weeks (see Reddy et al., 1975 for comparable results). Because of their higher metabolic rate (see Speakman, 2005) blood turnover is likely to be faster in smaller species, thus we decided that sampling every 15 days should provide a fair estimate of the condition of the birds (see below) in the preceding 2-3 weeks. We recorded the species, sex and size (tarsus length $[\mathrm{mm}]$ and weight $[\mathrm{g}]$ ) and took a blood sample $(\sim 5 \mu \mathrm{l})$ from each bird in a heparinized capillary tube after puncturing the brachial vein. Birds were marked with individual combinations of colored plastic rings and one metal ring with a unique number. We identified the nest of each pair with the aid of binoculars and visited each nest to check attendance by the parents and to record the clutch and brood size. Only one of the 58 nests followed was deserted, and it happened before egg-laying (the nest is not included in the analyses). The remaining 57 nests were followed until their chicks fledged. Within $12 \mathrm{~h}$ of collection we took the blood samples to the laboratory where we prepared two smears of each individual, to which we applied Schiff staining and counterstained with Hematoxylin. A coverslip was fitted with Entellan resin to each smear, which was inspected under a phase contrast optic microscope (Carl Zeiss ${ }^{\mathrm{TM}}$ Axiostar at a 1000X). We assessed 1000 erythrocytes from each smear (two smears per individual), counting every instance of a cell with micronuclei, nuclear buds, bridges in binucleated cells, and binucleated cells. At the end of the season we collected each focal nest, removed its parasites with a Berlese-Tullgen funnel, and separated and weighed all its component materials (Suárez-Rodríguez et al., 2013). We obtained the proportion of cigarette butts by dividing the butts weight between the total weight of the nest.

\section{Statistical Analyses}

We captured and recaptured 41 parents from 26 nests of Carpodacus mexicanus and 55 parents from 31 nests of Passer domesticus. We analyzed separately the two species, applying 
one generalized linear model to each, to determine which of our independent variables explained the number of blood cells with genotoxic damage (declaring a Poisson distribution for our dependent variable) using Rx64 s 3.1.2 software. Factors included were breeding stage (four levels), sex (two levels) and weight of cigarette butts in the nest (continuous variable).

After looking at the results we detected that there was an increment in the genotoxic damage experienced by males during the last two breeding stages. At this point, males make the bulk of the contribution to the feeding of the chicks. So, we explored whether the genotoxic damage was actually different from that experienced by females (see results and Figures 2, 4) applying generalized linear models using only the data from the last two stages (early breeding and late breeding) and declaring a Poisson distribution for our dependent variable. We selected the best model using the Akaike Information Criterion (AIC) and $\triangle \mathrm{AIC}$, with $\triangle \mathrm{AIC}<2$ indicating that two models were equally supported by the data.

\section{RESULTS}

\section{Carpodacus Mexicanus}

We obtained two models that best explained the number of erythrocytes with evidence of genotoxicity (see Table S1). The best model was a three-way interactive model of the three potentially explanatory factors (proportion of cigarette butts, sex and breeding stage). The amount of cigarette butts in the nest was positively associated with the level of female, but not of male, genotoxic damage (Table 1). This effect was evident during nest building, and during incubation; it was much less pronounced during early- (Figure 2), but again very substantial in late breeding (Table 1; Figure 2). Thus the level of genotoxicity experienced by females during breeding is both large and linked to the amount of cigarette butts in the nest (Table 1; Figure 2).

Males had fewer red-blood cells with signs of genotoxic damage, and their number was consistently independent of the amount of cigarette butts incorporated into the nests. However, the number of damaged cells increased through the breeding stages and appeared to be larger than the damage in females at the last breeding stage (Table 1; Figure 2). We evaluated whether breeding effort could explain the increase in male genotoxic damage (for instance through endogenous oxidative stress) by running a new model-selection procedure restricted to the early and late breeding stages, and incorporating brood size as a novel predictive factor. The model that best explains the amount of genotoxic damage includes an interaction between sex and brood size. It demonstrates that males attending larger broods had evidence of more genotoxic damage than males attending smaller broods (Figure 3). Female genotoxic damage was unrelated to brood size (Table 2; Figure 3).

\section{Passer Domesticus}

The number of cells with evidence of genotoxic damage in $P$. domesticus was best explained by a three-way (sex, cigarette butts and stage of breeding) interactive model (Table S4). In this case, damage in both males and females during nest construction and incubation seemed positively influenced by the amount of cigarette butts in the nest (Table 3; Figure 4). However, during nest building, incubation and early breeding females had more cells with evidence of genotoxic damage than males. As we

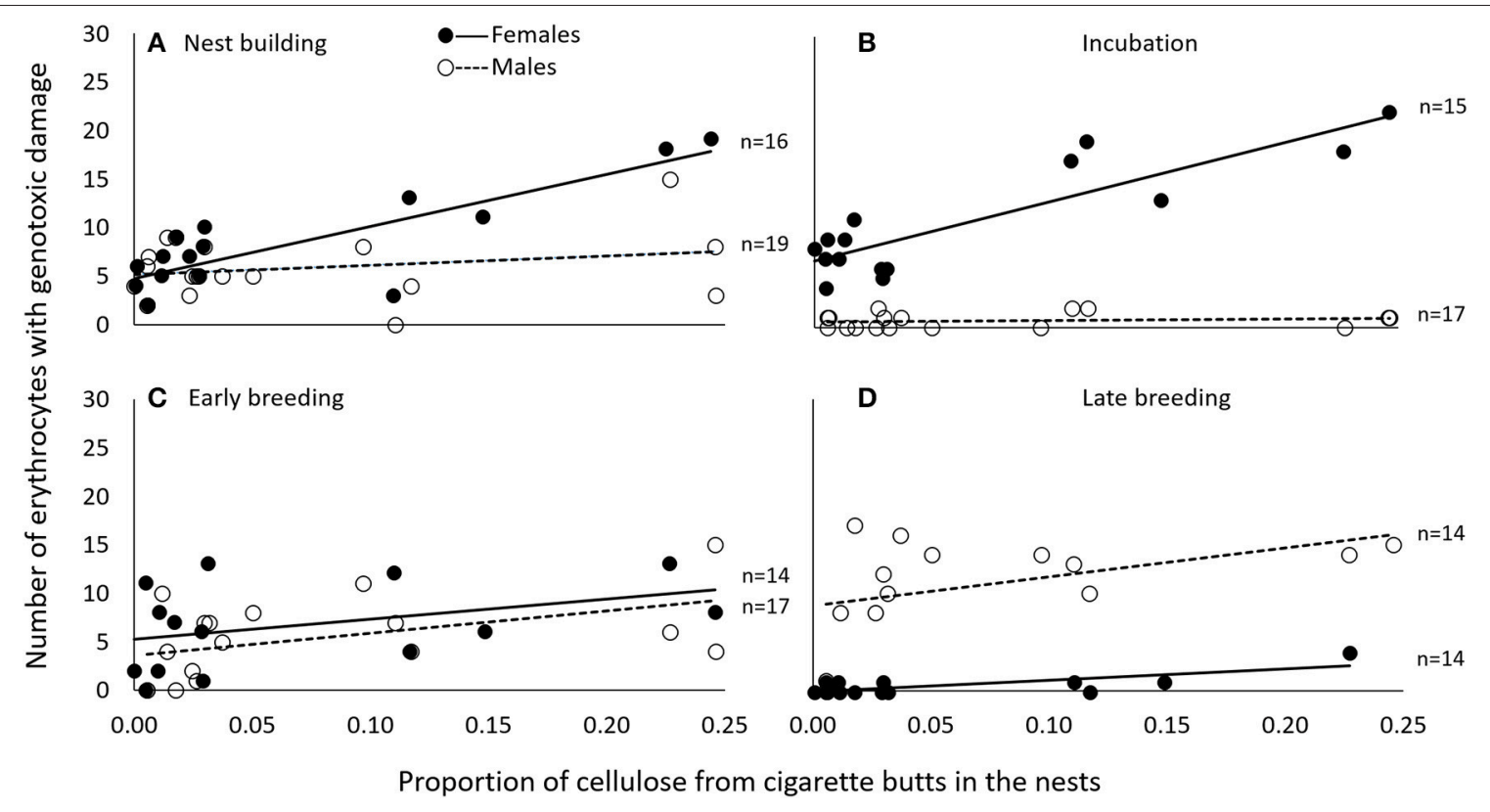

FIGURE 2 | During nest building (A) and incubation (B), genotoxic damage (expressed as the number of cells with nuclear abnormalities per 2000 erythrocytes) was associated in female C. mexicanus with the amount of cigarette butts incorporated into the nest. This was not the case during early (C) or late breeding (D). Variables are represented in the original scale to facilitate interpretation, but data were analyzed using generalized linear models. 
TABLE 1 | Comparison of effects of cigarette butts, sex and breeding stage on the amount of genotoxic damage (number of red-blood cells with nuclear abnormalities per 2000 cells) in C. mexicanus.

\begin{tabular}{lccccc}
\hline Breeding moment & \multicolumn{2}{c}{ Intercept } & & \multicolumn{2}{c}{ Slope } \\
\cline { 2 - 3 } \cline { 5 - 6 } & Females & Males & & Females & Males \\
\hline Nest building & 1.656 & 1.652 & & $5.241^{\star}$ & 1.523 \\
Incubation & $1.983^{\star}$ & -0.501 & & $4.657^{\star}$ & 1.842 \\
Early breeding & 1.668 & 1.347 & & 2.788 & $3.666^{\star}$ \\
Late breeding & -1.563 & $2.189^{\star}$ & & $12.335^{\star}$ & 2.454 \\
\hline
\end{tabular}

Coefficients ${ }^{1}$ come from the best supported model (see Table S1). Model = amount of cigarette butts $\times$ sex $\times$ breeding stage. Intercept = amount of damage at the onset of the breeding stage; Slope ${ }^{1}=$ steepness of the association between amount of cigarette butts in nest and genotoxic damage; ${ }^{*}=$ significant difference between sexes. (An analysis in which each nest is represented only by one if the parents, and only on one breeding stage, yielded essentially the same results; see Tables S8, S9).

${ }^{1}$ Both intercepts and slopes in the table are composite (added) values of different coefficients ( $\beta$ ) in the full model (see explanation in Table S3).

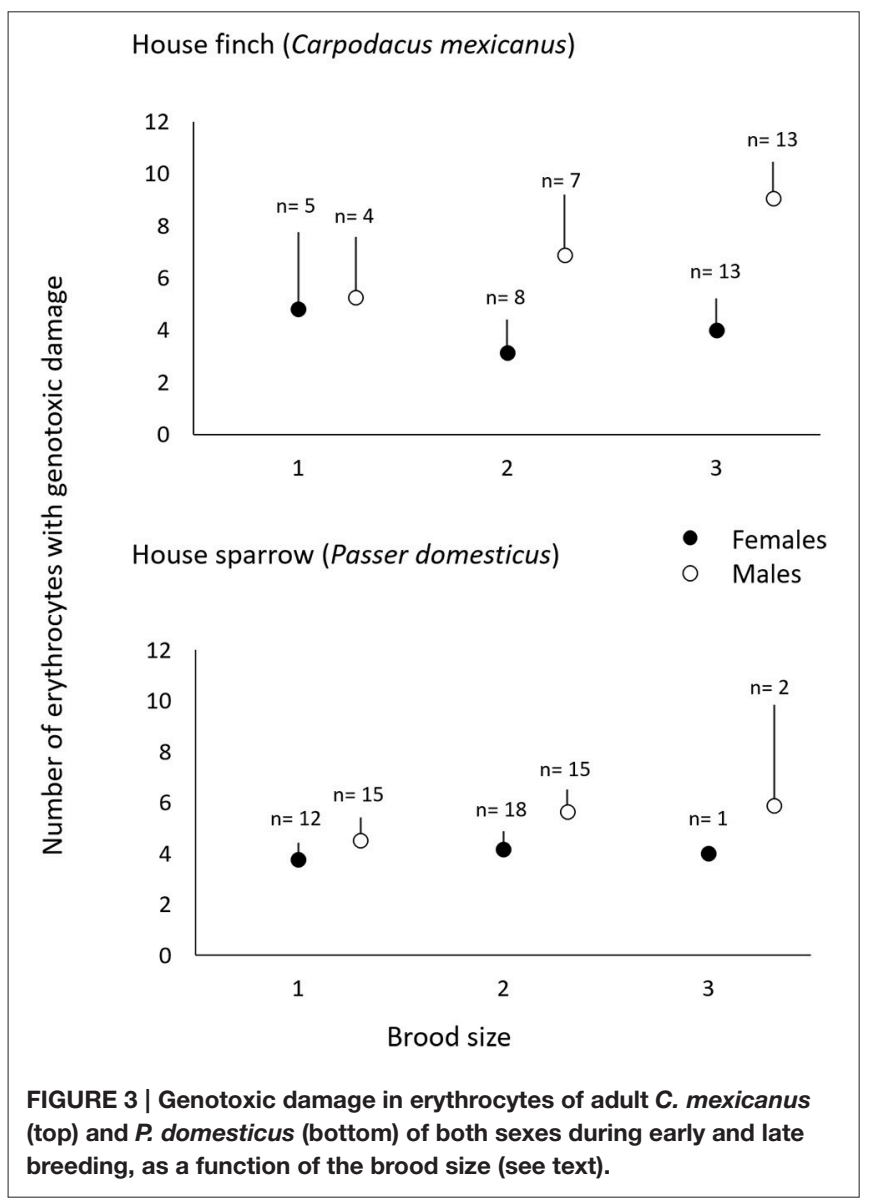

expected, the association between amount of cigarette butts in the nest and genotoxic damage was lowest in the last two breeding stages, when parents no longer occupy the nest. However, males had more genotoxic damage than females at the late breeding stage. (Table 3; Figure 4).

The number of erythrocytes with signs of genotoxic damage in males increased above the number of such cells in females
TABLE 2 | Results of the best model that explains the amount of genotoxic damage in erythrocytes of male Carpodacus mexicanus at the last two stages of reproduction (early and late breeding, entered together in the analysis so as not to atomize the sample size).

\begin{tabular}{lrrrr}
\hline Variables & Coefficient & SE & Z & $\boldsymbol{P}$ \\
\hline Intercept & 1.569 & 0.204 & 7.685 & $<0.001$ \\
Sex: males & 0.118 & 0.281 & 0.420 & 0.675 \\
Brood size: 2 chicks & -0.429 & 0.286 & -1.502 & 0.133 \\
Brood size: 3 chicks & -0.182 & 0.247 & -0.739 & 0.460 \\
Sex: males x brood size: 2 chicks & 0.689 & 0.373 & 1.846 & 0.065 \\
Sex: males x brood size: 3 chicks & 0.710 & 0.326 & 2.178 & 0.029
\end{tabular}

Model $=$ sex $\times$ brood size; females and one-chick broods are coded as zero, hence their contribution is included in the intercept.

TABLE 3 | Comparison of effects of cigarette butts, sex and breeding stage on the amount of genotoxic damage (number of red-blood cells with nuclear abnormalities per 2000 cells) in $P$. domesticus.

\begin{tabular}{lccccr}
\hline Breeding moment & \multicolumn{2}{c}{ Intercept } & & \multicolumn{2}{c}{ Slope } \\
\cline { 2 - 3 } & Females & Males & & Females & Males \\
Nest building & $1.997^{*}$ & 0.954 & & 2.696 & 4.709 \\
Incubation & $2.001^{*}$ & 0.271 & & 4.009 & 5.614 \\
Early breeding & $1.688^{*}$ & 0.918 & & -1.060 & -0.261 \\
Late breeding & 0.844 & $2.148^{*}$ & & -0.811 & -0.294
\end{tabular}

Coefficients ${ }^{1}$ come from the best supported model (see Table S4). Model = amount of cigarette butts $x$ sex $x$ breeding stage. Intercept = amount of damage at the onset of the breeding stage; Slope = steepness of the association between amount of cigarette butts in nest and genotoxic damage; * = significant difference between sexes. (An analysis in which each nest is represented only by one if the parents, and only on one breeding stage, yielded essentially the same results; see Tables S10, S11).

${ }^{1}$ Both intercepts and slopes in the table are composite (added) values of different coefficients in the full model (see explanation in Table S6).

during late breeding, and it was not related to the amount of nest cigarette butts. Consequently, we tested whether, as in $C$. mexicanus, this increase could be explained by endogenous stress related to the effort of feeding chicks. We thus ran the same model-selection procedure looking for a differential effect of brood size on genotoxic damage in male and female parents. Males showed more evidence of genotoxic damage than females during early and late chick breeding, but this damage was not associated with brood size in either sex (Table 4; Figure 3).

\section{DISCUSSION}

We found fluctuating levels of genotoxic damage -measured as the number of red-blood cells with nuclear abnormalitiesin breeding $P$. domesticus and $C$. mexicanus of both sexes. In females, at least during the early stages of the breeding attempt (nest building and incubation) such damage can be expressed as a function of the amount cigarette butts that they use to build their nest, and thus reveals a novel breeding cost for birds nesting in cities. This effect is evident in female C. mexicanus, which are in contact with the material during nest building and incubation, and in both members of $P$. domesticus, as 


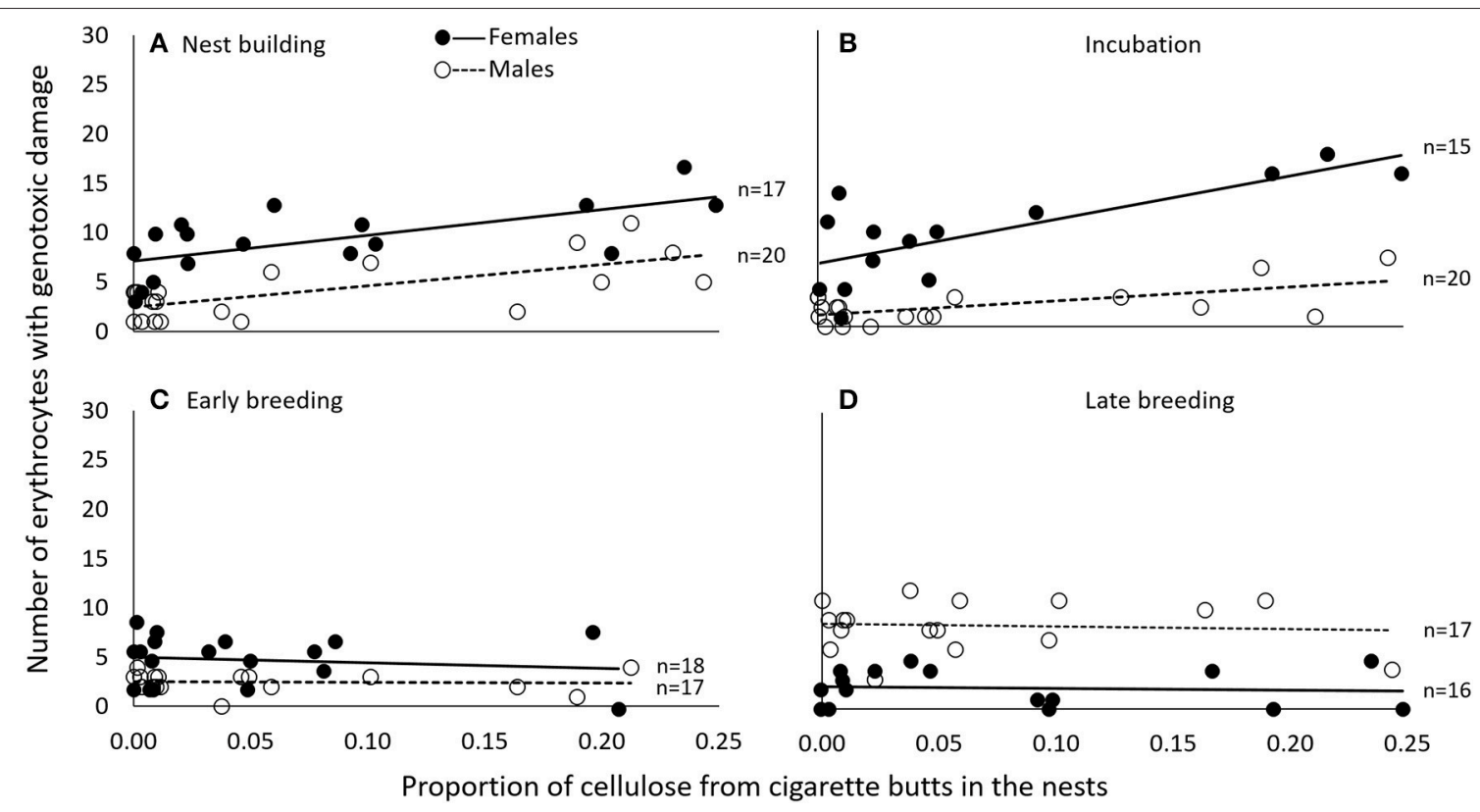

FIGURE 4 | During nest building (A) and incubation (B), genotoxic damage (expressed as the number of cells with nuclear abnormalities per 2000 erythrocytes) was associated in female and in male P. domesticus with the amount of cigarette butts incorporated into the nest. This was not the case during early (C) or late breeding (D). Variables are represented in the original scale to facilitate biological interpretation, but data were analyzed using generalized linear models.

they share the activities that lead to exposure with cigarette butts. Our results might be explained as a consequence of differences in health or condition between sexes or species. Yet this would not explain the significant link between the amount of butts in the nest and the numbers of erythrocytes with evidence of genotoxic damage; this was found in the sex most exposed to cigarette butts, and was found in the period when it is in a prolonged, direct contact with them. Since foraging is not restricted to areas where cigarette butts are abundant, we have no evidence of sex-specific diets in these species, and given that butts are never so copious that they may substantially leak toxicants into the ecosystem, we think that our results cannot be explained as a result of species/sex differences in diet.

We argue that nuclear abnormalities reveal physiological costs because they are the result of genotoxic damage, and thus can be a proxy to estimate oxidative stress (Bartsch, 2002; Valko et al., 2004) such as that generated by exposure to toxic substances (Fenech, 1993; DeMarini, 2004; Valko et al., 2004; Skarphedinsdottir et al., 2010; López Gordillo, 2012). In addition to revealing damage, abnormalities in the nuclei of erythrocytes can inform approximately when it took place. This is because birds filter their blood through the spleen in cycles of approximately 15-30 days (Rodnan et al., 1956), thus between one half and the whole of the red-blood cells are replaced approximately every 2 weeks, which is similar to the duration of each of the breeding stages that we defined, and hence the span of time between our consecutive samples. Therefore, our measure of genotoxic damage and our sampling program allow us to explore the consequences of exposure to discarded cigarette butts during particular moments of the breeding cycle, when the relative commitment of males and females to the breeding effort may vary.

Our data not only reveal a novel breeding cost for urban birds, but show these costs to be unequally shared by both sexes. Male and female C. mexicanus play different roles in parental care (Badyaev and Hill, 2002; Duckworth et al., 2003). Females build the nest, which means they, and not the males, manipulate all the materials that go into its construction. They also perform all the incubation (Badyaev and Hill, 2002; Hill, 2002; Duckworth et al., 2003), thus being virtually continuously in contact with the nest materials. Accordingly, we found that not only females had more evidence of damage than males, but the number of nuclear abnormalities in their blood was tightly correlated with the amount of cellulose fibers from cigarette butts in their nests (= amount of cigarette butts). By contrast, during the same stages the males had very few damaged erythrocytes, and their numbers were independent of the amount of butts that went into the nest construction. This is evidence that a novel, anthropogenic nest material can generate breeding costs that are a function of the sexual differences in parental roles.

Males of Carpodacus mexicanus were apparently unaffected by the amount of cigarette butts in their nests, but they also showed evidence of genotoxic damage, particularly later in the breeding attempt. In C. mexicanus, males deliver food to the nest (Badyaev and Hill, 2002); this does not bring them into direct contact with nest-lining but there could be a certain amount of exposure to the toxic material, thus inducing variable amounts of genotoxicity. Furthermore, providing food is a demanding activity, particularly after hatching and increasingly so as fledging approaches. Exertions such as this can raise the level of oxidative stress, and we propose that this is the explanation of the increase 
TABLE 4 | Results of the best model that explains the amount of genotoxic damage in erythrocytes of male Passer domesticus at the last two stages of reproduction (early and late breeding entered together in the analysis so as not to atomize the sample size).

\begin{tabular}{lcccc}
\hline Variables & Coefficient & SE & Z & $\boldsymbol{P}$ \\
\hline Intercept & 1.276 & 0.120 & 10.668 & $<0.001$ \\
Sex: males & 0.279 & 0.119 & 2.335 & 0.020 \\
Brood size: 2 chicks & 0.173 & 0.123 & 1.403 & 0.161 \\
Brood size: 3 chicks & 0.204 & 0.267 & 0.762 & 0.446 \\
\hline
\end{tabular}

Model = sex + brood size; females and one-chick broods are coded as zero, hence their contribution is included in the intercept.

in the number of nuclear abnormalities in male erythrocytes in the last two breeding stages (Figure 2), and of the apparent association of genotoxic damage with brood size (Figure 3).

Data from $P$. domesticus were also consistent with our prediction that exposure to cigarette butts promote genotoxic damage in breeding birds. In this case, however, the association between cigarette butts and nuclear abnormalities during nest building was indistinguishable between males and females (Figure 4). This may be due to the fact that male and female house sparrow participate in the construction of the nest and in the incubation off eggs (Bartlett et al., 2005). That the association was weaker in males during incubation is consistent with their reduced share in this activity (Figure 4). Thus, as in C. mexicanus, we uncover a breeding cost resulting from the use of anthropogenic nest materials by urban birds. Furthermore, we confirm that the extent of such cost is linked to the roles played by each pair member during the breeding effort.

In females of both species damage to the red-blood cells was reduced during early and late breeding, and in female house sparrows it was unrelated to the amount of cigarette butts that went into the making of the nest. Nor were nuclear abnormalities in females related to the number of chicks being raised, but we have little statistical power to detect such an effect.

Females of $C$. mexicanus show a late-breeding increase in genotoxic damage, which is linked, once more, to the amount of cigarette butts in the nest. We studied the genotoxic damage of birds raising their first brood, but since our population of C. mexicanus make several successive breeding attempts every year, and given their reported practice of clutch overlap (Evenden, 1957), we propose that the cigarette butt related increase in female nuclear abnormalities during late breeding is the consequence of renewed exposure to the nest lining due to incubation of a new clutch (as we systematically monitored the colony, we were able to detect clutch overlap). However, females do not build a new nest, but rather lay new eggs in the old one, thus exposure to butts, and hence genotoxic damage, are only moderately increased at this time. Indeed, we have witnessed clutch overlap within a nest, starting as early as when the chicks were approximately 5 days old.

The nests of $C$. mexicanus and $P$. domesticus contain the same proportion of cigarette butts (Suárez-Rodríguez et al., 2013), yet there appears to be more genotoxic damage in the former (see Supplementary materials). If confirmed, this pattern could be the consequence of male and female sparrows sharing, and thus diluting, the effect of exposure to cigarette butts, yet in both species the extent of damage is similar during early breeding, but lower in house sparrows than in finches (compare Figures 2C, 4C). Another possibility is that this interspecific difference indicates that $P$. domesticus, with a long urban history that should have brought it into contact with anthropogenic pollutants, may have developed adaptations such as enhanced enzymatic activity (e.g., Rainio et al., 2012), that increase its ability to detoxify itself (Schwagmeyer and Mock, 2003). This tantalizing possibility would constitute one of very few cases of phenotypic adjustments to cities that may not be explained just a consequence of plasticity, but as genuine adaptation to urban life (see Suárez-Rodríguez et al. in press).

While we are confident that our measures of nuclear abnormalities are indicative of genotoxic damage, we have no inkling on what the long term consequences of this damage may be. Indeed, there is a paucity of works on the effects of toxicity on the longevity of short-lived Passerine birds. To be of consequence, genotoxicity-the damage of genetic material during cell division- should result in mutagenesis, which involves a modification of the genetic code that is transferred to the next generation of cells (Fenech, 2008). As we worked with cells that are constantly being produced and replaced (Rodnan et al., 1956), it may be that even if exposure to cigarette butts results in mutagenesis, this may not have time to express itself before the cell carrying it being discarded, unless the damage took place in erythropoietic stem cells, which would continue producing damaged erythrocytes. We counted nuclear abnormalities in erythrocytes because 1) their short life span allowed us to track the possible association between breeding activity and damage, and 2) extracting small amounts of blood to make two smears is both easy and relatively little intrusive. Still, damage may be occurring to other cell lineages -notably in the germ line- and in tissues or organs where it may have a more consequential effect on the condition, life expectancy and fertility of birds.

We have uncovered genotoxic consequences of breeding activities of birds using anthropogenic nest materials, and show that the amount of damage is linked to the roles played by both sexes during breeding. Cigarette butts repel nest parasites (Suárez-Rodríguez et al., 2013), presumably because they contain nicotine (Harvey et al., 2007), and arsenic (Slaughter et al., 2011) which have been used as insecticides, as well as polycyclic aromatic hydrocarbons and other metals which could be responsible for the genotoxic damage experienced by both chicks (Suárez-Rodríguez and Macías Garcia, 2014) and adults (this work). Birds in nature also utilize some particular (plant) materials to deter parasites off the nest (Clark and Mason, 1988; Lafuma et al., 2001; Brouwer and Komdeur, 2004; Ontiveros et al., 2007; Gwinner and Berger, 2008; Polo et al., 2010), and it is conceivable that some of the substances involved (Gwinner and Berger, 2006) are also harmful to the birds. Still, both the diversity and the concentration of substances in discarded, smoked-through cigarette butts are likely to be much higher than those found in plants brought to the nests for prophylaxis, and we propose that the costs reported here apply mainly, if not only to birds using cigarette butts to line their nests. On the other hand, the ubiquitous application of insecticides and herbicides 
to crops, and their subsequent leaking into non-agricultural habitats, should make the exposure of birds to toxicants from nest materials a global reality, with consequences on the costs paid by the parents in accordance to their respective parental roles. This increasing risk of exposure to anthropogenic pollutants could elevate the cost of nest-building and incubation, with potentially negative demographic consequences.

\section{ETHICS STATEMENT}

In conducting this research, we adhered to the guidelines for the use of animals in research. We minimized handling stress, kept the sample to the minimum necessary to test the working hypotheses, and verified that no mortality happened as a result of our manipulations. This report has been approved by an adhoc ethical committee set up by the Programa Universitario de Bioética (UNAM).

\section{AUTHOR CONTRIBUTIONS}

CG and MS designed the study. MS collected the data, performed the analyses, and generated an initial draft of the report. CG provided logistical support and edited the manuscript. RM advised on the measure of toxicological damage, which was conducted in her facilities. All authors reviewed and approved the final version.

\section{FUNDING}

MS was awarded a PhD scholarship (480142/280493) by the Consejo Nacional de Ciencia y Tecnología (CONACyT), and CG

\section{REFERENCES}

Antczak, M., Hromada, M., Czechowski, P., Tabor, J., Zablocki, P., Grzybek, J., et al. (2010). A new material for old solutions-the case of plastic string used in Great Grey Shrike nests. Acta Ethol. 13, 87-91. doi: 10.1007/s10211-0100077-2

Badyaev, A. V., and Hill, G. E. (2002). Paternal care as a conditional strategy: distinct reproductive tactics associated with elaboration of plumage ornamentation in the house finch. Behav. Ecol. 13, 591-597. doi: 10.1093/beheco/13.5.591

Baldwin, J. M. (1896). A new factor in evolution. Am. Nat. 30, 441-451. doi: $10.1086 / 276408$

Bartlett, T. L., Mock, D. W., and Schwagmeyer, P. L. (2005). Division of labor: incubation and biparental care in house sparrows (Passer domesticus). Auk 122, 835-842. doi: 10.1642/0004-8038(2005)122[0835:DOLIAB]2.0.CO;2

Bartsch, H. (2002). Hunting for electrophiles that harm human DNA: frits sobels award lecture. Mutagenesis 17, 281-287. doi: 10.1093/mutage/17.4.281

Bennett, W. A. (1990). Scale of investigation and the detection of competition: an example from the house sparrow and house finch introductions in North America. Am. Nat. 135, 725-747. doi: 10.1086/285071

Bent, A., and Austin, O. (1968). Life Histories of North American Cardinals, Grosbeaks, Buntings, Towhees, Finches, Sparrows, and Allies: Order Passeriformes: Family Fringillidae. Part 1. New York, NY: Dover Publications.

Bermúdez-Cuamatzin, E., Ríos-Chelén, A. A., Gil, D., and Macías Garcia, C. (2010). Experimental evidence for real-time song frequency shift in response to urban noise in a passerine bird. Biol. Lett. 7, 36-38. doi: 10.1098/rsbl.201 0.0437 contributed to the research expenses using the budget allocated to him by the Instituto de Ecología, UNAM.

\section{ACKNOWLEDGMENTS}

We thank S. Vargas, A. Vargas, T. Nakamura and V. Argaez for field work help. José J. Zúñiga-Vega, R. Torres, and J. Schondube advised on methodological and statistical aspects and provided commentaries to early drafts. Edgar Ávila provided logistical support. Field work was facilitated by A. Martínez Sigüenza from the Coordinación de Áreas Verdes y Forestación of the Dirección General de Obras y Conservación, UNAM, and by L. Gómez Pérez and J. Andraca Lara of the Dirección General de Presupuesto and the Instituto de Investigaciones Filológicas, UNAM. Luis Serrano-García, Soledad Solís Ángeles, and Omar Arellano-Aguilar advised on and provided logistical support for conducting the genotoxicity analyses. Also, we thank Lynna Kiere for her English revision. This paper is a partial fulfillment for MS's doctoral degree within the Posgrado en Ciencias Biológicas, UNAM under the supervision of CG. MS was the recipient of a scholarship from CONACyT. This research counted with the Ministry for the Environment (SEMARNAT) permit SGPA/DGVS/00610/13. The authors declare that we have no conflict of interest.

\section{SUPPLEMENTARY MATERIAL}

The Supplementary Material for this article can be found online at: http://journal.frontiersin.org/article/10.3389/fevo. 2017.00004/full\#supplementary-material

Brouwer, L., and Komdeur, J. (2004). Green nesting material has a function in mate attraction in the european starling. Anim. Behav. 67, 539-548. doi: 10.1016/j.anbehav.2003.07.005

Cavia, R., Cueto, G., and Suárez, O. (2009). Changes in rodent communities according to the landscape structure in an urban ecosystem. Landsc. Urban Plan. 90, 11-19. doi: 10.1016/j.landurbplan.2008.10.017

Clark, L., and Mason, J. R. (1987). Olfactory discrimination of plant volatiles by the european starling. Anim. Behav. 35, 227-235. doi: 10.1016/S0003-3472(87)80228-2

Clark, L., and Mason, J. R. (1988). Effect of biologically active plants used as nest material and the derived benefit to starling nestlings. Oecologia 77, 174-180. doi: 10.1007/BF00379183

Clayton, D. H., Koop, J. A. H., Harbison, C. W., Moyer, B. R., and Bush, S. E. (2010). How birds combat ectoparasites. Open Ornithol. J. 3, 41-71. doi: $10.2174 / 1874453201003010041$

Collias, N. E. (1964). The evolution of nests and nest-building in birds. Am. Zool. 4, 175-190. doi: 10.1093/icb/4.2.175

DeMarini, D. M. (2004). Genotoxicity of tobacco smoke and tobacco smoke condensate: a review. Mutat. Res. Mutat. Res. 567, 447-474. doi: 10.1016/j.mrrev.2004.02.001

Ditchkoff, S. S., Saalfeld, S. T., and Gibson, C. J. (2006). Animal behavior in urban ecosystems: modifications due to human-induced stress. Urban Ecosyst. 9, 5-12. doi: 10.1007/s11252-006-3262-3

Duckworth, R. A., Badyaev, A. V., and Parlow, A. F. (2003). Elaborately ornamented males avoid costly parental care in the house finch (Carpodacus mexicanus): a proximate perspective. Behav. Ecol. Sociobiol. 55, 176-183. doi: 10.1007/s00265-003-0671-7 
Evenden, F. G. (1957). Observations on nesting behavior of the house finch. Condor 59, 112-117. doi: $10.2307 / 1364571$

Fenech, M. (1993). The cytokinesis-block micronucleus technique and its application to genotoxicity studies in human populations. Environ. Health Perspect. 101, 101-107. doi: 10.2307/3431708

Fenech, M. (1997). The advantages and disadvantages of the cytokinesis-block micronucleus method. Mutat. Res. Toxicol. Environ. Mutagen. 392, 11-18. doi: 10.1016/S0165-1218(97)00041-4

Fenech, M. (2007). Cytokinesis-block micronucleus cytome assay in lymphocytes. Nature 2, 1084-1104. doi: 10.1038/nprot.2007.77

Fenech, M. (2008). The micronucleus assay determination of chromosomal level DNA damage. Methods Mol. Biol. 2008, 185-216. doi: 10.1007/978-1-59745-548-0_12

Fry, D. M. (1995). Reproductive effects in birds exposed to pesticides and industrial chemicals. Environ. Health Perspect. 103:165. doi: 10.1289/ehp.95103 s7165

Gil, D., Honarmand, M., Pascual, J., Pérez-Mena, E., and Macías Garcia, C. (2014). Birds living near airports advance their dawn chorus and reduce overlap with aircraft noise. Behav. Ecol. 25, 435-443. doi: 10.1093/beheco/aru207

Gorissen, L., Snoeijs, T., Van Duyse, E., and Eens, M. (2005). Heavy metal pollution affects dawn singing behaviour in a small passerine bird. Oecologia 145, 504-509. doi: 10.1007/s00442-005-0091-7

Gross, K., Pasinelli, G., and Kunc, H. P. (2010). Behavioral Plasticity Allows Short-Term Adjustment to a Novel Environment. Am. Nat. 176, 456-464. doi: $10.1086 / 655428$

Gwinner, H., and Berger, S. (2006). Parasite defence in birds: the role of volatiles. Acta Zool. Sin. 52, 280-283.

Gwinner, H., and Berger, S. (2008). Starling males select green nest material by olfaction using experience-independent and experience-dependent cues. Anim. Behav. 75, 971-976. doi: 10.1016/j.anbehav.2007.08.008

Hamer, G. (2003). Solid waste treatment and disposal: effects on public health and environmental safety. Biotechnol. Adv. 22, 71-79. doi: 10.1016/j.biotechadv.2003.08.007

Hartwig, E., Clemens, T., and Heckroth, M. (2007). Plastic debris as nesting material in a Kittiwake-(Rissa tridactyla)-colony at the Jammerbugt, Northwest Denmark. Mar. Pollut. Bull. 54, 595-597. doi: 10.1016/j.marpolbul.2007.01.027

Harvey, J. A., Van Dam, N. M., Witjes, L. M. A., Soler, R., and Gols, R. (2007). Effects of dietary nicotine on the development of an insect herbivore, its parasitoid and secondary hyperparasitoid over four trophic levels. Ecol. Entomol. 32, 15-23. doi: 10.1111/j.1365-2311.2006.00838.x

Hill, G. (2002). A Red Bird in a Brown Bag: the Function and Evolution of Colorful Plumage in the House Finch. New York, NY: Oxford University Press.

Hilton, G. M., Hansell, M. H., Ruxton, G. D., Reid, J. M., and Monaghan, P. (2004). Using artificial nests to test importance of nesting material and nest shelter for incubation energetics. Auk 121, 777-787. doi: 10.1642/0004-8038(2004)121[0777:UANTTI]2.0.CO;2

Hoi, H., Václav, R., and Slobodová, D. (2003). Postmating sexual selection in house sparrows: can females estimate "good fathers" according to their early paternal effort? Folia Zool. 52, 299-308.

Hovland, N., Andreassen, H., and Ims, R. (1999). Foraging behaviour of the root vole Microtus oeconomus in fragmented habitats. Oecologia 121, 236-244. doi: $10.1007 /$ s004420050925

Hund, A. K., Blair, J. T., and Hund, F. W. (2015). A review of available methods and description of a new method for eliminating ectoparasites from bird nests. J. F. Ornithol. 86, 191-2014. doi: 10.1111/jofo.12113

Jensenl, T. K., Jørgensen, N., Punab, M., Haugen, T. B., Suominen, J., Zilaitiene, B., et al. (2004). Association of in utero exposure to maternal smoking with reduced semen quality and testis size in adulthood: a cross-sectional study of 1,770 young men from the general population in five european countries. Am. J. Epidemiol. 159, 49-58. doi: 10.1093/aje/kwh002

Kalinoski, R. (1975). Intra- and interspecific aggression in house finches and house sparrows. Condor 77, 375-384. doi: 10.2307/1366086

Lafuma, L., Lambrechts, M. M., and Raymond, M. (2001). Aromatic plants in bird nests as a protection against blood-sucking flying insects? Behav. Process. 56, 113-120. doi: 10.1016/S0376-6357(01)00191-7

Liker, A., Papp, Z., Bókony, V., and Lendvai, Á. Z. (2008). Lean birds in the city: body size and condition of house sparrows along the urbanization gradient. $J$. Anim. Ecol. 77, 789-795. doi: 10.1111/j.1365-2656.2008.01402.x
Linnaeus, C. (1758). Systema Naturae per Regna Tria Naturae, Secundum Classes, Ordines, Genera, Species, Cum Characteribus, Differentiis, Synonymis, Locis (in Latin). I, 10th revised Edn. Holmius: Laurentius Salvius.

López Gordillo, A. P. (2012). Evaluación de da-o Genotóxico y Citotóxico por Exposición Simultánea a Cloroformo, Diclorometano y Tolueno y su Relación con el Metabolismo de fase II. Mexico: Universidad Nacional Autónoma de México.

López-Rull, I., and Macías Garcia, C. (2015). "Control of invertebrate occupants of nests," in Nests, Eggs, and Incubation, eds D. C. Deeming and S. J. Reynolds (Oxford: Oxford University Press), 82-96.

Lowther, P. E., and Cink, C. L. (2006). "House Sparrow (Passer domesticus)," in The Birds of North America, ed A. Poole (Ithaca, NY: Cornell Laboratory of Ornithology), 1-19.

Markman, S., Leitner, S., Catchpole, C., Barnsley, S., Müller, C. T., Pascoe, D., et al. (2008). Pollutants increase song complexity and the volume of the brain area HVC in a songbird. PLoS ONE 3:e1674. doi: 10.1371/journal.pone.0001674

McClure, C. J. W., Estep, L. K., and Hill, G. E. (2011). A multi-scale analysis of competition between the house finch and house sparrow in the southeastern United States. Condor 113, 462-468. doi: 10.1525/cond.2011.100061

Mennerat, A., Mirleau, P., Blondel, J., Perret, P., Lambrechts, M. M., and Heeb, P. (2009a). Aromatic plants in nests of the blue tit Cyanistes caeruleus protect chicks from bacteria. Oecologia 161, 849-855. doi: 10.1007/s00442-009-1418-6

Mennerat, A., Perret, P., Bourgault, P., Blondel, J., Gimenez, O., Thomas, D. W., et al. (2009b). Aromatic plants in nests of blue tits: positive effects on nestlings. Anim. Behav. 77, 569-574. doi: 10.1016/j.anbehav.2008.11.008

Miller, J. R., and Hobbs, R. J. (2002). Conservation where people live and work. Conserv. Biol. 16, 330-337. doi: 10.1046/j.1523-1739.2002.00420

Moriwaki, H., Kitajima, S., and Katahira, K. (2009). Waste on the roadside,poisute'waste: its distribution and elution potential of pollutants into environment. Waste Manag. 29, 1192-1197. doi: 10.1016/j.wasman.2008.08.017

Müller, O. F. (1776). Zoologicae Danicae Prodromus, seu Animalium Daniae et Norvegiae Indigenarum Characteres, Nomina et Synonyma Imprimis Popularium. Copenhagen: Hallageriis, Havniae.

Nolan, P. M., and Hill, G. E. (2004). Female choice for song characteristics in the house finch. Anim. Behav. 67, 403-410. doi: 10.1016/j.anbehav.2003.03.018

Ontiveros, D., Caro, J., and Pleguezuelos, J. M. (2007). Green plant material versus ectoparasites in nests of Bonelli's eagle. J. Zool. 274, 1-6. doi: 10.1111/j.1469-7998.2007.00364.x

Polo, V., López-Rull, I., Gil, D., and Veiga, J. P. (2010). Experimental addition of green plants to the nest increases testosterone levels in female spotless starlings. Ethology 116, 129-137. doi: 10.1111/j.1439-0310.2009.01724.x

Price, T. D., Qvarnström, A., and Irwin, D. E. (2003). The role of phenotypic plasticity in driving genetic evolution. Proc. R. Soc. B Biol. Sci. 270, 1433-1440. doi: 10.1098/rspb.2003.2372

Rainio, M. J., Kanerva, M., Wahlberg, N., Nikinmaa, M., and Eeva, T. (2012). Variation of basal EROD activities in ten passerine bird species - relationships with diet and migration status. PLOS ONE 7:e33926. doi: 10.1371/journal.pone.0033926

Rathcke, B. J., and Jules, E. S. (1993). Habitat fragmentation and plant-pollinator. Curr. Sci. 65, 273-277.

Reddy, P. R. K., Van Krey, H. P., Gross, W. B., and Siegel, P. B. (1975). Erythrocyte lifespan in dwarf and normal pullets from growth selected lines of chickens. Poult. Sci. 54, 1301-1303. doi: 10.3382/ps.0541301

Register, K. M. (2013). Cigarette butts as litter- toxic as well as ugly. Underw. Nat. $10,23-29$.

Rodnan, G. P., Ebaugh, F. G., and Spivey Fox, M. R. (1956). The life span of the red blood cell and the red blood cell volume in the chicken, pigeon and duck as estimated by the use of Na2Cr51O4. Blood 12, 355-366.

Schtickzelle, N., Mennechez, G., and Baguette, M. (2006). Dispersal depression with habitat fragmentation in the bog fritillary butterfly. Ecology 87, 1057-1065. doi: 10.1890/0012-9658(2006)87[1057:DDWHFI]2.0.CO;2

Schwagmeyer, P. L., and Mock, D. W. (2003). How consistently are good parens good parents? repeatability of parental care in the house sparrow, Passer domesticus. Ethology 109, 303-313. doi: 10.1046/j.1439-0310.2003. 00868.x

Schwagmeyer, P. L., Schwabl, H. G., and Mock, D. W. (2005). Dynamics of biparental care in house sparrows: hormonal manipulations of paternal contributions. Anim. Behav. 69, 481-488. doi: 10.1016/j.anbehav.2004. 04.017 
Sih, A. (2013). Understanding variation in behavioural responses to humaninduced rapid environmental change: a conceptual overview. Anim. Behav. 85, 1077-1088. doi: 10.1016/j.anbehav.2013.02.017

Sih, A., Bolnick, D. I., Luttbeg, B., Orrock, J. L., Peacor, S. D., Pintor, L. M., et al. (2010). Predator-prey naïveté, antipredator behavior, and the ecology of predator invasions. Oikos 119, 610-621. doi: 10.1111/j.1600-0706.2009.18039.x

Sih, A., Ferrari, M. C. O., and Harris, D. J. (2011). Evolution and behavioural responses to human-induced rapid environmental change. Evol. Appl. 4, 367-387. doi: 10.1111/j.1752-4571.2010.00166.x

Skarphedinsdottir, H., Hallgrimsson, G. T., Hansson, T., Hägerroth, P.-Å., Liewenborg, B., Tjärnlund, U., et al. (2010). Genotoxicity in herring gulls (Larus argentatus) in Sweden and Iceland. Mutat. Res. Toxicol. Environ. Mutagen. 702, 24-31. doi: 10.1016/j.mrgentox.2010.07.002

Slabbekoorn, H. (2013). Songs of the city: noise-dependent spectral plasticity in the acoustic phenotype of urban birds. Anim. Behav. 85, 1-11. doi: 10.1016/j.anbehav.2013.01.021

Slaughter, E., Gersberg, R. M., Watanabe, K., Rudolph, J., Stransky, C., and Novotny, T. E. (2011). Toxicity of cigarette butts, and their chemical components, to marine and freshwater fish. Tob. Control 20, I25-I29. doi: 10.1136/tc.2010.040170

Speakman, J. R. (2005). Body size, energy metabolism and lifespan. J. Exp. Biol. 208, 1717-1730. doi: 10.1242/jeb.01556

Suárez-Rodríguez, M., López-Rull, I., and Macías Garcia, C. (2013). Incorporation of cigarette butts into nests reduces nest ectoparasite load in urban birds: new ingredients for an old recipe? Biol. Lett. 9:20120931. doi: 10.1098/rsbl.2012.0931

Suárez-Rodríguez, M., and Macías Garcia, C. (2014). There is no such a thing as a free cigarette; lining nests with discarded butts brings short-term benefits, but causes toxic damage. J. Evol. Biol. 27, 2719-2726. doi: 10.1111/jeb.12531

Tanner, C., Salalı, G., and Jackson, A. (2011). Feeding and non-feeding aggression can be induced in invasive shore crabs by altering food distribution. Behav. Ecol. Sociobiol. 65, 249-256. doi: 10.1007/s00265-010-1033-x

Townsend, A. K., and Barker, C. M. (2014). Plastic and the nest entanglement of urban and agricultural crows. PLoS ONE 9:e88006. doi: 10.1371/journal.pone.0088006

Tscharntke, T., and Brandl, R. (2004). Plant-insect interactions in fragmented landscapes. Annu. Rev. Entomol. 49, 405-430. doi: 10.1146/annurev.ento.49. 061802.123339

Valero, A., Macías Garcia, C., and Magurran, A. E. (2008). Heterospecific harassment of native endangered fishes by invasive guppies in mexico. Biol. Lett. 4, 149-152. doi: 10.1098/rsbl.2007.0604

Valko, M., Izakovic, M., Mazur, M., Rhodes, C. J., and Telser, J. (2004). Role of oxygen radicals in DNA damage and cancer incidence. Mol. Cell. Biochem. 266, 37-56. doi: 10.1023/B:MCBI.0000049134.69131.89
Van Riper, C. III. (1976). Aspects of house finch breeding biology in hawaii. Condor 78, 224-229. doi: 10.2307/1366857

Veiga, J. P., Polo, V., and Vi-uela, J. (2006). Nest green plants as a male status signal and courtship display in the spotless starling. Ethology 112, 196-204. doi: 10.1111/j.1439-0310.2006.01148.x

Voltura, K. M., Schwagmeyer, P. L., and Mock, D. W. (2002). Parental feeding rates in the house sparrow, Passer domesticus: are larger-badged males better fathers? Ethology 108, 1011-1022. doi: 10.1046/j.1439-0310.2002. 00831

Votier, S. C., Archibald, K., Morgan, G., and Morgan, L. (2011). The use of plastic debris as nesting material by a colonial seabird and associated entanglement mortality. Mar. Pollut. Bull. 62, 168-172. doi: 10.1016/j.marpolbul.2010. 11.009

Wang, Y., Chen, S., Blair, R. B., Jiang, P., and Ding, P. (2009). Nest composition adjustments by Chinese Bulbuls Pycnonotus sinensis in an urbanized landscape of Hangzhou (E China). Acta Ornithol. 44, 185-192. doi: $10.3161 / 000164509$ X482768

Wimberger, P. H. (1984). The use of green plant material in bird nests to avoid ectoparasites. Auk 101, 615-618.

Wink, M. (1988). Plant breeding: importance of plant secondary metabolites for protection against pathogens and herbivores. Theor. Appl. Genet. 75, 225-233. doi: 10.1007/BF00303957

Witschi, H., Espiritu, I., Dance, S. T., and Miller, M. S. (2002). A mouse lung tumor model of tobacco smoke carcinogenesis. Toxicol. Sci. 68, 322-330. doi: $10.1093 /$ toxsci/68.2.322

Wittstock, U., and Gershenzon, J. (2002). Constitutive plant toxins and their role in defense against herbivores and pathogens. Curr. Opin. Plant Biol. 5, 300-307. doi: 10.1016/S1369-5266(02)00264-9

Woods, R. S. (1968). "House Finch," in Life Histories of North American Cardinals, Grosbeaks, Buntings, Towhees, Finches, Sparrows, and Allies. Part I, ed A. C. Bent (New York, NY: Dover), 290-314.

Conflict of Interest Statement: The authors declare that the research was conducted in the absence of any commercial or financial relationships that could be construed as a potential conflict of interest.

Copyright (c) 2017 Suárez-Rodríguez, Montero-Montoya and Macías Garcia. This is an open-access article distributed under the terms of the Creative Commons Attribution License (CC BY). The use, distribution or reproduction in other forums is permitted, provided the original author(s) or licensor are credited and that the original publication in this journal is cited, in accordance with accepted academic practice. No use, distribution or reproduction is permitted which does not comply with these terms. 